\title{
Red-Shifted Absorptions of Cation-Defective and Surface- Functionalized Anatase with Enhanced Photoelectrochemical Properties
}

Jiwei Ma, ${ }^{* \dagger, \ddagger \odot(0) ~ W e i ~ L i, ~}{ }^{\ddagger}$ Nikolay T. Le, ${ }^{\S}$ Jesús A. Díaz-Real, ${ }^{\|}$Monique Body, ${ }^{\perp}$ Christophe Legein, ${ }^{\perp}(0)$

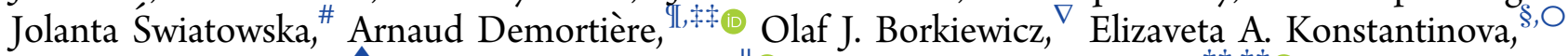

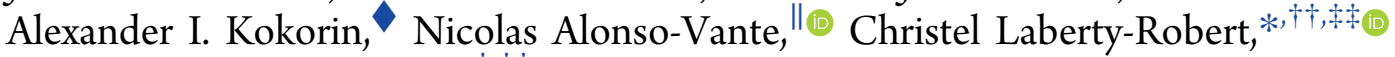
and Damien Dambournet ${ }^{*+*, \neq}$

\footnotetext{
${ }^{\dagger}$ Institute of New Energy for Vehicles, School of Materials Science and Engineering, Tongji University, Shanghai 201804, China

‡Sorbonne Université, CNRS, Physico-chimie des Électrolytes et Nano-systèmes Interfaciaux, PHENIX, F-75005 Paris, France

${ }^{\S}$ Department of Physics, Moscow State University, Moscow 119991, Russia

"IC2MP, UMR-CNRS 7285, Université de Poitiers, 4 rue Michel Brunet, F-86073 Poitiers, France

${ }^{\perp}$ Institut des Molécules et Matériaux du Mans (IMMM)—UMR 6283 CNRS, Le Mans Université, Avenue Olivier Messiaen, 72085 Le Mans Cedex 9, France

\#PSL Research University, CNRS-Chimie ParisTech, Institut de Recherche de Chimie Paris (IRCP), 11 rue Pierre et Marie Curie, 75005 Paris, France

IL Laboratoire de Réactivité et Chimie des Solides, CNRS UMR 7314, Université de Picardie Jules Verne, 33 rue Saint Leu, 80039 Amiens Cedex, France

${ }^{\nabla}$ X-ray Science Division, Advanced Photon Source, Argonne National Laboratory, Argonne, Illinois 60439, United States

ONational Research Center Kurchatov Institute, Moscow 123182, Russia

$\checkmark$ N. Semenoy Institute of Chemical Physics RAS, Moscow 119991, Russia

${ }^{\dagger}$ Sorbonne Université, CNRS, Collège de France, Laboratoire de Chimie de la Matière Condensée de Paris, F-75005 Paris, France

${ }^{*}$ Réseau sur le Stockage Electrochimique de l'Energie (RS2E), FR CNRS 3459, 80039 Amiens Cedex, France
}

Supporting Information

ABSTRACT: Manipulating the atomic structure of semiconductors is a fine way to tune their properties. The rationalization of their modified properties is, however, particularly challenging as defects locally disrupt the long-range structural ordering, and a deeper effort is required to fully describe their structure. In this work, we investigated the photoelectrochemical properties of an anatase-type structure featuring a high content of titanium vacancies stabilized by dual-oxide substitution by fluoride and hydroxide anions. Such atomic modification induces a slight red-shift band gap energy of $0.08 \mathrm{eV}$ as compared to pure $\mathrm{TiO}_{2}$, which was assigned to changes in titaniumanion ionocovalent bonding. Under illumination, electron paramagnetic resonance spectroscopy revealed the formation of $\mathrm{Ti}^{\mathrm{III}}$ and $\mathrm{O}_{2}{ }^{-}$radicals which were not detected in defect-free $\mathrm{TiO}_{2}$. Consequently, the modified anatase shows higher ability to oxidize water with lower electron-hole recombination rate. To further increase the photoelectrochemical properties, we subsequently modified the compound by a surface functionalization with $N$-methyl-2-pyrrolidone (NMP). This treatment further

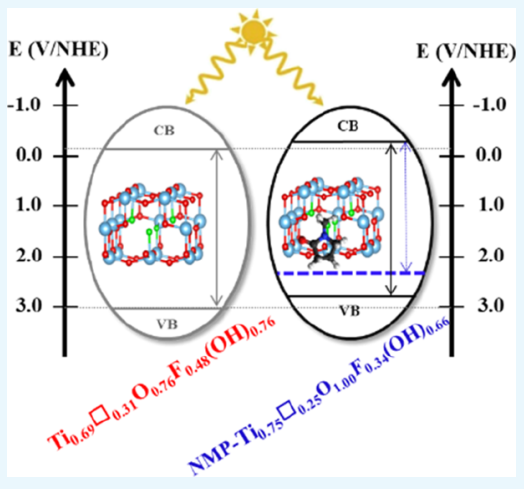
modifies the chemical composition, which results in a red shift of the band gap energy to $3.03 \mathrm{eV}$. Moreover, the interaction of the NMP electron-donating molecules with the surface induces an absorption band in the visible region with an estimated band gap energy of 2.25-2.50 eV. Under illumination, the resulting core-shell structure produces a high concentration of reduced $\mathrm{Ti}^{\mathrm{III}}$ and $\mathrm{O}_{2}{ }^{-}$, suggesting an effective charge carrier separation which is confirmed by high photoelectrochemical properties. This work provides new opportunities to better understand the structural features that affect the photogenerated charge carriers.

\section{INTRODUCTION}

Owing to its semiconductor character enabling light-induced productions of charge carriers, titanium dioxide has been largely investigated. ${ }^{1}$ In particular, the pioneering work of
Received: April 28, 2019

Accepted: June 11, 2019

Published: June 24, 2019 
Fujishima and Honda on water splitting ${ }^{2}$ led to intensive research on photoelectrochemical systems using $\mathrm{TiO}_{2}$ including photoelectrochemical water splitting, photocatalysis, and dye-sensitized solar cells. ${ }^{3}$ However, current limitations of (anatase) $\mathrm{TiO}_{2}$ are a limited light absorption due to a band gap energy of $3.2 \mathrm{eV}$ yielding an absorption of less than $5 \%$ of the incident solar radiation and a rapid recombination of electrons and holes produced upon photoexcitation. ${ }^{4,5}$

Enabling the practical uses of $\mathrm{TiO}_{2}$ as photoelectrodes requires a concomitant red-shift light adsorption into the visible light range and an improved charge separation upon photoexcitation. This can be achieved by using different strategies including surface engineering and/or doping/ substitution with heteroatoms. ${ }^{1,6,7}$ In the latter strategy, metallic and nonmetallic dopants can produce donor/acceptor states in the band gap of $\mathrm{TiO}_{2}$ to effectively extend the light adsorption into the visible light range. ${ }^{8,9}$ Cationic metal dopants, however, produce localized $\mathrm{d}$ states deep in the band gap of $\mathrm{TiO}_{2}$ and create new recombination centers for electrons and holes.'

Among all anionic dopants, fluoride is unique because it can act as both a morphology director and electron scavenger to reduce the recombination rate of charge carriers. ${ }^{9-15}$ There is, however, no clear understanding on how fluorine doping affects the band gap energy and the photoactivity of anatase $\mathrm{TiO}_{2}{ }^{12,14-17}$ Czoska et al. ${ }^{15}$ reported that fluorine doping of $\mathrm{TiO}_{2}$ did not show a red shift in the visible light region nor reacted with absorbed $\mathrm{O}_{2}$ to form superoxide radicals. $\mathrm{Li}$ et al. ${ }^{16}$ demonstrated that fluorine doping did not produce any effect on the optical absorption of $\mathrm{TiO}_{2}$, although a high visible photocatalytic activity was achieved because of the creation of surface oxygen vacancies. On the contrary, Calatayud et al. ${ }^{14}$ reported that lattice fluorine doping enabled a $0.2 \mathrm{eV}$ decrease of the band gap energy. Yu et al. ${ }^{12}$ previously reported that the F-doped $\mathrm{TiO}_{2}$ showed stronger absorption in the UV-visible range and a red shift. Overall, such discrepancies might come from the nature of defects induced by the partial substitution of $\mathrm{O}^{2-}$ by $\mathrm{F}^{-}$. For instance, the stabilization of fluorine through a mechanism of valence induction, ${ }^{14}$ that is, $\mathrm{Ti}^{\mathrm{IV}}{ }_{(1-x)} \mathrm{Ti}^{\mathrm{III}}{ }_{x} \mathrm{O}_{(2-x)} \mathrm{F}_{x}$, yielded a $0.2 \mathrm{eV}$ decrease of the band gap energy. In this substitutional mechanism, the presence of $\mathrm{Ti}^{\mathrm{III}}$ centers is suggested to be the physical origin of the reduced band gap. ${ }^{8-19}$

Another substitutional mechanism associates the formation of titanium vacancies $(\square)$ through the partial substitution of divalent $\mathrm{O}^{2-}$ by monovalent $\mathrm{F}^{-}$and $\mathrm{OH}^{-}$. This gives the opportunity to better understand the impact of particular structural features related to the presence of $\mathrm{F}^{-}, \mathrm{OH}^{-}$, and vacancies on the band gap energy and the photogenerated carriers.

Experimentally, nanoparticles of anatase featuring the general chemical formula $\mathrm{Ti}_{1-x-y} \square_{x+y} \mathrm{O}_{2-4(x+y)} \mathrm{F}_{4 x}(\mathrm{OH})_{4 y}$ can be synthetized by a sol-gel process activated under mild solvothermal conditions. ${ }^{20}$ This synthesis method allows to stabilize anisotropic particles with a large percentage of reactive (001) facets along with a high concentration of titanium vacancies arising from a large substitution rate of $\mathrm{O}^{2-}$ by $\mathrm{F}^{-} /$ $\mathrm{OH}^{-21,22}$

In the present paper, we report the study of the impact of titanium vacancies on the band gap energy and the trapping of photoexcited electrons and holes. The reactivity of the charge carriers diffusing to the surface was monitored by photoelectrochemical measurements. Anatase
$\mathrm{Ti}_{1-x-y} \square_{x+y} \mathrm{O}_{2-4(x+y)} \mathrm{F}_{4 x}(\mathrm{OH})_{4 y}$ shows a 2-fold enhancement of quantum efficiency with a slight band gap reduction of 0.08 $\mathrm{eV}$ as compared to anatase $\mathrm{TiO}_{2}$. Furthermore, we took advantages of the high concentration of under-coordinated $\mathrm{Ti}$ to functionalize the surface by a donor molecule, that is, $\mathrm{N}$ methyl-2-pyrrolidone (NMP), which further allows reducing the band gap and reaching a 5 times higher quantum efficiency as compared to anatase $\mathrm{TiO}_{2}$.

\section{RESULTS AND DISCUSSION}

\subsection{Cation-Defective Anatase} $\left(\mathrm{Ti}_{1-x-y} \square_{x+y} \mathrm{O}_{2-4(x+y)} \mathrm{F}_{4 x}(\mathrm{OH})_{4 y}\right)$. The cation-defective anatase was prepared by a previously reported method employing solgel chemistry performed in the presence of Hydrofluoric acid (HF). This method allows to stabilize the nanoparticles of anatase having the general chemical formula $\mathrm{Ti}_{1-x-y} \square_{x+y} \mathrm{O}_{2-4(x+y)} \mathrm{F}_{4 x}(\mathrm{OH})_{4 y}$, where $\square$ represents a titanium vacancy formed by the negative charge deficiency induced by the partial substitution of oxide by fluoride and hydroxide anions (Figure S1). ${ }^{20}$ In the present study, a compound featuring a high concentration $(x+y)$ of titanium vacancy was prepared (see the Experimental Section). The accurate chemical composition was assessed by determining the vacancy concentration through structural refinement of the pair distribution function (PDF) data, the fluorine content was determined by ${ }^{19} \mathrm{~F}$ solid-state nuclear magnetic resonance (NMR), and the $\mathrm{OH}$ content was deduced by electroneutrality leading overall to $\mathrm{Ti}_{0.69} \square_{0.31} \mathrm{O}_{0.76} \mathrm{~F}_{0.48}(\mathrm{OH})_{0.76 \cdot}{ }^{20,23}$ For comparison purpose, the cation-defective free anatase $\mathrm{TiO}_{2}$ was prepared. Powder X-ray diffraction (XRD) confirms the phase purities of both anatase samples (Figure S2). The optical absorption properties of anatase $\mathrm{TiO}_{2}$ and $\mathrm{Ti}_{0.69} \square_{0.31} \mathrm{O}_{0.76} \mathrm{~F}_{0.48}(\mathrm{OH})_{0.76}$ were investigated by UV-vis absorption spectroscopy (Figure 1). Doped and undoped

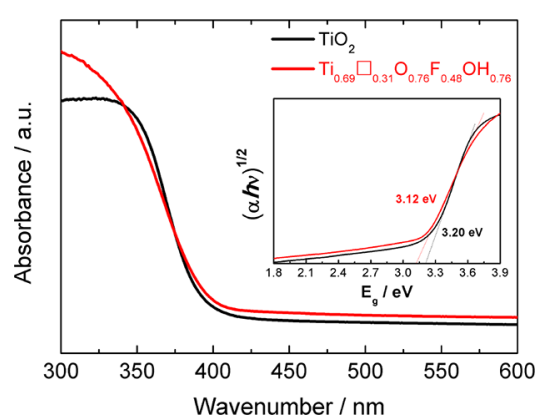

Figure 1. UV-vis absorption spectra of anatase $\mathrm{TiO}_{2}$ and $\mathrm{Ti}_{0.69} \square_{0.31} \mathrm{O}_{0.76} \mathrm{~F}_{0.48}(\mathrm{OH})_{0.76}$. (Inset: Kubelka-Munk vs photon energy plots for anatase $\mathrm{TiO}_{2}$ and $\mathrm{Ti}_{0.69} \square_{0.31} \mathrm{O}_{0.76} \mathrm{~F}_{0.48}(\mathrm{OH})_{0.76}$.)

anatase showed an absorption edge within the 350-400 nm range, which corresponds to the typical charge transfer region of $\mathrm{O}(2 \mathrm{p})-\mathrm{Ti}(3 \mathrm{~d}) .^{24}$ Although the deduced band gap energy is $3.2 \mathrm{eV}$ for anatase $\mathrm{TiO}_{2}$, the band gap energy of $\mathrm{Ti}_{0.69} \square_{0.31} \mathrm{O}_{0.76} \mathrm{~F}_{0.48}(\mathrm{OH})_{0.76}$ is red-shifted to $3.12 \mathrm{eV}$. For $\mathrm{TiO}_{2}$, the conduction band is characterized by the $3 \mathrm{~d}$ states of $\mathrm{Ti}$ and the valence band is composed of the $2 \mathrm{p}$ orbitals of $\mathrm{O}^{2-}$. In the case of $\mathrm{Ti}_{0.69} \square_{0.31} \mathrm{O}_{0.76} \mathrm{~F}_{0.48}(\mathrm{OH})_{0.76}$, the valence band is composed of the $2 \mathrm{p}$ orbitals of $\mathrm{O}^{2-}, \mathrm{F}^{-}$, and $\mathrm{OH}^{-}$. It was shown that the $2 \mathrm{p}$ states of $\mathrm{F}^{-}$ions are localized rather at the bottom of the valence band, hence leading to a higher band gap energy. ${ }^{25}$ On the other hand, $\mathrm{OH}$ groups were proposed to decrease the band gap energy value of a titanium 
hydroxyfluoride compound featuring titanium vacancies. ${ }^{26} \mathrm{We}$ propose that the observed reduction of the band gap energy observed is due to the presence of $\mathrm{OH}$ groups in larger quantity than $\mathrm{F}^{-}$ions.

Electron paramagnetic resonance (EPR) spectra were recorded (Figure 2) under dark and light irradiation (in the

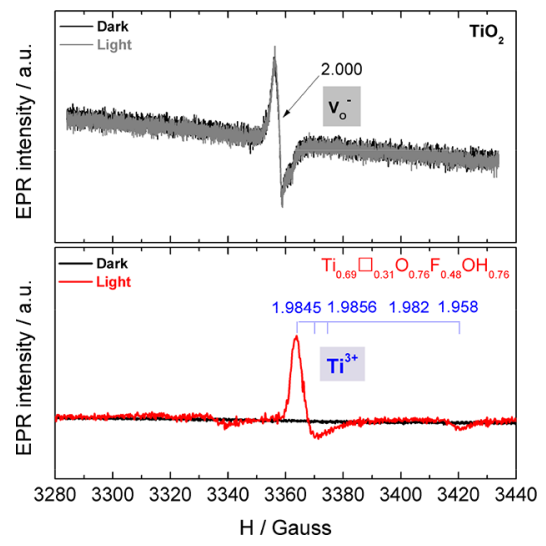

Figure 2. EPR spectra of anatase $\mathrm{TiO}_{2}$ and $\mathrm{Ti}_{0.69} \square_{0.31} \mathrm{O}_{0.76} \mathrm{~F}_{0.48}(\mathrm{OH})_{0.76}$ at $T=77 \mathrm{~K}$ under dark and illumination.

spectral range of $250-1000 \mathrm{~nm}$ ) to investigate the ability of the anatase samples to generate paramagnetic centers (PCs), that is, radicals and reduced $\mathrm{Ti}^{27-30}$ The anatase $\mathrm{TiO}_{2}$ EPR signal features a slightly asymmetrical shape and a $g$-factor value of 2.000 which can be assigned to electrons trapped at oxygen vacancies $\left(\mathrm{V}_{\mathrm{O}}+\mathrm{e}=\mathrm{V}_{\mathrm{O}}{ }^{-}\right){ }^{31}$ The EPR signal of such oxygen vacancies in $\mathrm{TiO}_{2}$ does not change with illumination. The most likely reason for this phenomenon may be because the defects act as recombination centers of the photogenerated electrons and holes. Therefore, the amplitude of the EPR signal does not change with irradiation. Such species can contribute to the absorption of light in the visible range because they can create levels in the forbidden band (impurity absorption). However, they are inactive for photoconversion, such as photocatalysis. Under dark condition, no PCs were detected for $\mathrm{Ti}_{0.69} \square_{0.31} \mathrm{O}_{0.76} \mathrm{~F}_{0.48}(\mathrm{OH})_{0.76}$ (Figure 2), in agreement with the sole presence of $\mathrm{Ti}^{\mathrm{IV}}$. Under illumination, a weak EPR signal at around 3300-3340 G, with $g_{1}=2024, g_{2}=2010$, and $g_{3}=2003$, is observed to be characteristic of $\mathrm{O}_{2}{ }^{-}$radicals. Furthermore, an intensive signal at 3350-3370 G with $g_{\perp}=$ 1.9845 and $g_{\|}=1.958$ assigned to $\mathrm{Ti}^{\mathrm{III}}$ (Figure 2) is also observed. In $\mathrm{TiO}_{2}$, the reduction of $\mathrm{Ti}^{\mathrm{IV}}$ is combined with the formation of oxygen vacancy or $\mathrm{OH}$ groups leading to $\mathrm{Ti}^{\mathrm{III}} /$ oxygen vacancy PCs. ${ }^{27,29}$ Moreover, the line width of the $\mathrm{Ti}^{\mathrm{III}}$ centers signal is small (approximately $15 \mathrm{G}$ ), suggesting that these PCs are isolated (no overlapping of the wave functions) and mainly localized in the bulk. Indeed, the dipole-dipole interaction between PCs localized on sample surface and surrounding paramagnetic oxygen molecules strongly increases the line width of the EPR signal. ${ }^{32}$

The photoelectrochemical properties of anatase $\mathrm{TiO}_{2}$ and $\mathrm{Ti}_{0.69} \square_{0.31} \mathrm{O}_{0.76} \mathrm{~F}_{0.48}(\mathrm{OH})_{0.76}$ were evaluated using linear sweep voltammetry recorded under dark and UV-vis light conditions. The photocurrent response (Figure 3a) was calculated by subtracting the current measured under dark from the current measured under UV-vis light. Overall, the measured activity for water oxidation was low, which is probably due to the porosity of the deposited film that might affect electronhole recombination, their electronic conductivity, and in fine the photocurrent density. However, the photocurrent response of $\mathrm{Ti}_{0.69} \square_{0.31} \mathrm{O}_{0.76} \mathrm{~F}_{0.48}(\mathrm{OH})_{0.76}$ is ca. 2 times higher than that of $\mathrm{TiO}_{2}$ at $0.70 \mathrm{~V}$ versus NHE. More interestingly, a shift of the onset potential is observed going from $0.10 \mathrm{~V}$ versus $\mathrm{NHE}$ for anatase $\mathrm{TiO}_{2}$ to $-0.10 \mathrm{~V}$ versus NHE for $\mathrm{Ti}_{0.69} \square_{0.31} \mathrm{O}_{0.76} \mathrm{~F}_{0.48}(\mathrm{OH})_{0.76}$ (Figure 3a).

The higher photocurrent and the negative shift of the photocurrent onset potential clearly indicate that the anatase $\mathrm{Ti}_{0.69} \square_{0.31} \mathrm{O}_{0.76} \mathrm{~F}_{0.48}(\mathrm{OH})_{0.76}$ exhibits lower electron-hole recombination rate compared to anatase $\mathrm{TiO}_{2}$. Because of the similar specific surface area for $\mathrm{TiO}_{2}\left(\sim 180 \mathrm{~m}^{2} \mathrm{~g}^{-1}\right.$, data not shown) and $\mathrm{Ti}_{0.69} \square_{0.31} \mathrm{O}_{0.76} \mathrm{~F}_{0.48}(\mathrm{OH})_{0.76}\left(\sim 190 \mathrm{~m}^{2} \mathrm{~g}^{-1}\right.$, data not shown), this phenomena can be related to the presence of surface and bulk defects in $\mathrm{Ti}_{0.69} \square_{0.31} \mathrm{O}_{0.76} \mathrm{~F}_{0.48}(\mathrm{OH})_{0.76}{ }^{33}$ It has been shown that $\mathrm{O}_{2}{ }^{-}$ radicals are very active species for photocatalytic processes, for example, to decompose toxic substances on oxide surface. Therefore, the presence of these radicals at the surface of $\mathrm{Ti}_{0.69} \square_{0.31} \mathrm{O}_{0.76} \mathrm{~F}_{0.48}(\mathrm{OH})_{0.76}$, upon light irradiation, might play
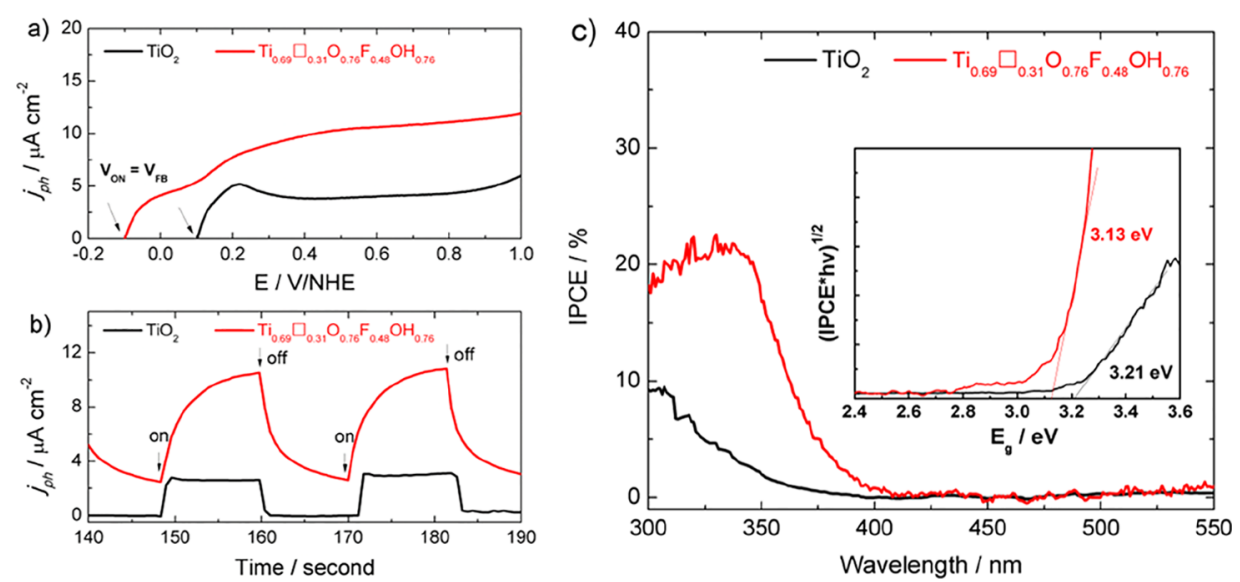

Figure 3. (a) $j_{\mathrm{ph}}-E$ plots under $\mathrm{UV}-$ vis irradiation and (b) photocurrent response with chopped light (frequency of $0.1 \mathrm{~s}^{-1}$ ) at $1 \mathrm{~V} / \mathrm{NHE}$ for TiO and $\mathrm{Ti}_{0.69} \square_{0.31} \mathrm{O}_{0.76} \mathrm{~F}_{0.48}(\mathrm{OH})_{0.76}$ in a $\mathrm{N}_{2}$-purged electrolyte $\left(1 \mathrm{M} \mathrm{Na}_{2} \mathrm{SO}_{4}, \mathrm{pH}=5\right)$. Scan rate is $5 \mathrm{mV} \mathrm{s}^{-1}$. The photoanode geometric surface area is $0.19 \mathrm{~cm}^{2}$. (c) IPCE spectra of $\mathrm{TiO}_{2}$ and $\mathrm{Ti}_{0.69} \square_{0.31} \mathrm{O}_{0.76} \mathrm{~F}_{0.48}(\mathrm{OH})_{0.76}$ photoanodes at $1 \mathrm{~V} / \mathrm{NHE}$. (Inset: Tauc plots for the direct optical transitions of $\mathrm{TiO}_{2}$ and $\mathrm{Ti}_{0.69} \square_{0.31} \mathrm{O}_{0.76} \mathrm{~F}_{0.48}(\mathrm{OH})_{0.76}$ photoanodes.) 
a role in the modification of the charge separation process observed between these two anatases.

To further illustrate this point, photocurrent transient measurements were performed to measure the charge recombination at the semiconductor/electrolyte interface. In Figure $3 b$, the evolution of the photocurrents is reported when light is turned on and off, with a frequency of $0.062 \mathrm{~Hz}$. Anatase $\mathrm{TiO}_{2}$ and $\mathrm{Ti}_{0.69} \square_{0.31} \mathrm{O}_{0.76} \mathrm{~F}_{0.48}(\mathrm{OH})_{0.76}$ show distinct behaviors. On the one hand, a sharp anodic transient photocurrent occurs upon illumination of $\mathrm{TiO}_{2}$, showing that the photogenerated holes move to the semiconductor/ electrolyte junction and accumulate (the carriers oxidize trap states in the bulk and on the surface). ${ }^{34}$ This is followed by photocurrent stabilization when equilibrium is reached between water oxidation and charge recombination. ${ }^{35}$ Conversely, when the light is turned off, the photocurrent decay is assigned to electrons recombining with the a c cumulated holes. Regarding anatase $\mathrm{Ti}_{0.69} \square_{0.31} \mathrm{O}_{0.76} \mathrm{~F}_{0.48}(\mathrm{OH})_{0.76}$, a gradually increase of the transient photocurrent is observed and a stabilization (stable photocurrent) occurs at a much longer time. These distinct behaviors are attributed to differences in equilibrium between the rate of water oxidation and charge recombination; a longer recombination rate of electron-holes was observed in the case of anatase $\mathrm{Ti}_{0.69} \square_{0.31} \mathrm{O}_{0.76} \mathrm{~F}_{0.48}(\mathrm{OH})_{0.76}$ where electrons are stabilized at the $\mathrm{Ti}^{1 I I}$ centers and then the electron-hole recombination rate is reduced.

To better understand the interplay between the photoelectrochemical activity and light absorption, the incident photon-to-current conversion efficiency (IPCE) of $\mathrm{Ti}_{0.69} \square_{0.31} \mathrm{O}_{0.76} \mathrm{~F}_{0.48}(\mathrm{OH})_{0.76}$ compared with that of $\mathrm{TiO}_{2}$ was evaluated using the following law: IPCE $=1239.8 j_{\mathrm{ph}} / \lambda P_{\mathrm{w}}{ }^{36}$ where $j_{\mathrm{ph}}$ is the measured photocurrent density $\left(\mathrm{mA} \mathrm{cm}^{-2}\right)$ and $P_{\mathrm{w}}$ is the incident power density $\left(\mathrm{mW} \mathrm{cm}^{-2}\right)$ at the wavelength $\lambda(\mathrm{nm})$. After applying the light source photoemission correction, the IPCE spectra (Figure 3c) show that $\mathrm{Ti}_{0.69} \square_{0.31} \mathrm{O}_{0.76} \mathrm{~F}_{0.48}(\mathrm{OH})_{0.76}$ exhibits an enhanced photoelectrochemical activity in the UV range as compared to $\mathrm{TiO}_{2}$, suggesting that the separation and transportation of photogenerated charge carriers occur more efficiently. The inset of Figure $3 \mathrm{c}$ shows the Tauc plot for a direct optical transition $(n=1 / 2)$ in $j_{\mathrm{ph}}=A\left(h \nu-E_{\mathrm{g}}\right)^{n} / h \nu{ }^{37}$ The linear extrapolation at the energy axis yields an $E_{\mathrm{g}}$ of $3.21 \mathrm{eV}$ for anatase $\mathrm{TiO}_{2}$, in agreement with literature data ${ }^{38}$ and an $E_{\mathrm{g}}$ of $3.13 \mathrm{eV}$ for $\mathrm{Ti}_{0.69} \square_{0.31} \mathrm{O}_{0.76} \mathrm{~F}_{0.48}(\mathrm{OH})_{0.76}$. This latter result agrees with the result obtained from the UV-vis absorbance spectrum.

\subsection{Surface Functionalization of Anatase} $\mathrm{Ti}_{0.69} \square \square_{0.31} \mathrm{O}_{0.76} \mathrm{~F}_{0.48}(\mathrm{OH})_{0.76}$. To improve the properties of anatase $\mathrm{Ti}_{0.69} \square_{0.31} \mathrm{O}_{0.76} \mathrm{~F}_{0.48}(\mathrm{OH})_{0.76}$, we used the absorption of donor molecules, an established way to modify properties. ${ }^{39,40}$ We found that the optical properties of $\mathrm{Ti}_{0.69} \square_{0.31} \mathrm{O}_{0.76} \mathrm{~F}_{0.48}(\mathrm{OH})_{0.76}$ can be modified when NMP molecules are adsorbed on its surface, as revealed by the yellowish color of the powder (Figure 4a,b). Such a surface modification was shown to be effective only on the anatase $\mathrm{Ti}_{0.69} \square_{0.31} \mathrm{O}_{0.76} \mathrm{~F}_{0.48}(\mathrm{OH})_{0.76}$. The coloration of the powder is observed by dispersing the powder into NMP (see the Experimental Section) for more than 3 days under air atmosphere. No coloration was observed when the experiment is performed under dry atmosphere (Figure S3). Then, it can be assumed that $\mathrm{H}_{2} \mathrm{O}$ molecules induce hydroxylation, which in turn enables the functionalization of the nanoparticles with
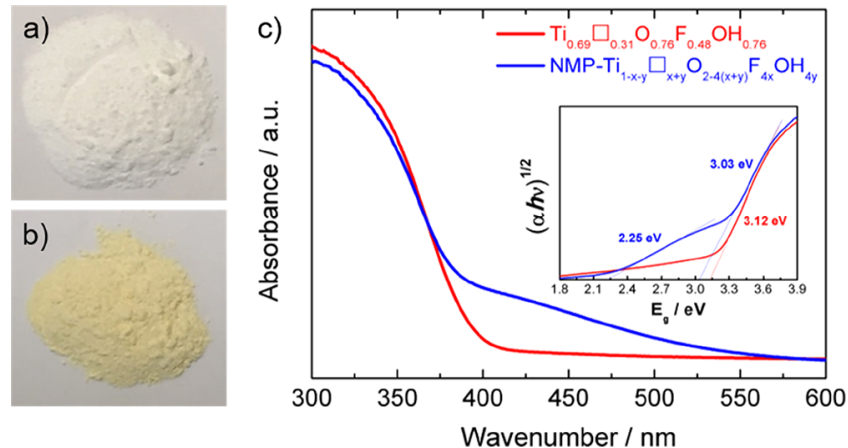

Figure 4. (a,b) Visual appearances and (c) UV-vis absorption spectra of anatase $\mathrm{Ti}_{0.69} \square_{0.31} \mathrm{O}_{0.76} \mathrm{~F}_{0.48}(\mathrm{OH})_{0.76}$ before and after NMP functionalization. (Inset: Kubelka-Munk vs photon energy plots for anatase $\mathrm{Ti}_{0.69} \square_{0.31} \mathrm{O}_{0.76} \mathrm{~F}_{0.48}(\mathrm{OH})_{0.76}$ before and after NMP functionalization.)

NMP molecules (Figure S4). These reactions are specific to $\mathrm{Ti}_{0.69} \square_{0.31} \mathrm{O}_{0.76} \mathrm{~F}_{0.48}(\mathrm{OH})_{0.76}$ because no color change was noticed for pure anatase $\mathrm{TiO}_{2}$ (Figure S5). Figure 4c shows the UV-vis absorption spectra of anatase $\mathrm{Ti}_{0.69} \square_{0.31} \mathrm{O}_{0.76} \mathrm{~F}_{0.48}(\mathrm{OH})_{0.76}$ before and after the surface functionalization with NMP molecules. The sample treated with NMP shows an additional absorption feature within the visible range, that is, $\sim 550 \mathrm{~nm}$, in agreement with its yellow color. Moreover, a plot of $(\alpha h \nu)^{1 / 2}$ versus $h \nu$ (see inset of Figure 4c) using the modified Kubelka-Munk method reveals a slight decrease of the band gap energy from 3.12 to $3.03 \mathrm{eV}$ and a second feature occurring at $2.25 \mathrm{eV}$.

Elemental analysis was performed at the level of an aggregate of nanoparticles of NMP-Ti $1_{1-x-y} \square_{x+y} \mathrm{O}_{2-4(x+y)} \mathrm{F}_{4 x}(\mathrm{OH})_{4 y}$ (Figure 5a). Elemental mapping (Figure $5 \mathrm{~b}-\mathrm{e}$ ) obtained by energy-dispersive X-ray spectroscopy (EDX) in a scanning transmission electron microscope revealed the presence of nitrogen atoms present in the whole area of the aggregate, suggesting a homogeneous grafting of NMP molecules at the surface of the nanoparticles.

The effective grafting of NMP molecules was also confirmed by X-ray photoelectron spectroscopy (XPS) analysis. The XPS spectrum of NMP-Ti $i_{1-x-y} \square_{x+y} \mathrm{O}_{2-4(x+y)} \mathrm{F}_{4 x}(\mathrm{OH})_{4 y}$ (Figure 6) shows the appearance of a $\mathrm{N} 1 \mathrm{~s}$ peak centered at $400.5 \mathrm{eV}$, which is characteristic of pyrrole nitrogen atom in NMP. ${ }^{41,42}$

2.2.1. Structure and Spectroscopic Analysis of NMPFunctionalized Anatase $\mathrm{Ti}_{1-x-y} \square_{x+y} \mathrm{O}_{2-4(x+y)} F_{4 x}(\mathrm{OH})_{4 y}$. To probe the structural impact of the NMP functionalization, we first performed XRD analysis which confirms that the longrange order remains intact after the NMP treatment (Figure S2). Subsequently, we used the PDF obtained by Fourier transformation of synchrotron-based XRD data to analyze any structural deviation occurring at the short-range order. Figure 7 shows the refined PDF patterns of $\mathrm{Ti}_{0.69} \square_{0.31} \mathrm{O}_{0.76} \mathrm{~F}_{0.48}(\mathrm{OH})_{0.76}$ and NMP $\mathrm{Ti}_{1-x-y} \square_{x+y} \mathrm{O}_{2-4(x+y)} \mathrm{F}_{4 x}(\mathrm{OH})_{4 y}$ samples. The extracted structural parameters are gathered in Table S1. Both anatase samples showed similar unit cell parameters and a close coherence length of ca. $4 \mathrm{~nm}$, suggesting that the long-range order was not modified upon functionalization. The refinement of the Ti site occupancy, however, shows a slight decrease of the titanium vacancy with site occupancies of ca. $69(3) \%$ for pristine $\mathrm{Ti}_{0.69} \square_{0.31} \mathrm{O}_{0.76} \mathrm{~F}_{0.48}(\mathrm{OH})_{0.76}$ sample and $75(2) \%$ for NMP- $\mathrm{Ti}_{1-x-y} \square_{x+y} \mathrm{O}_{2-4(x+y)} \mathrm{F}_{4 x}(\mathrm{OH})_{4 y}$ sample, indicating a 

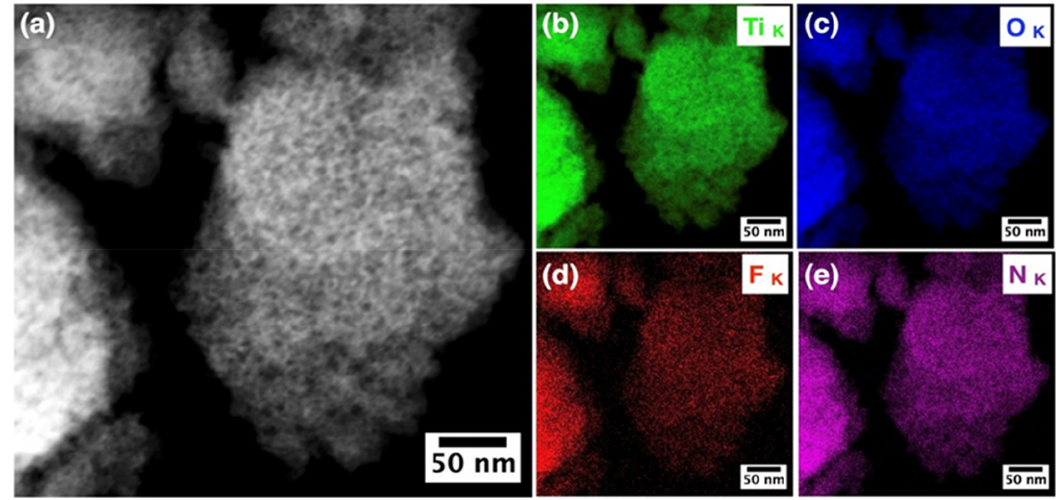

Figure 5. (a) STEM image at low magnification coupled with elemental mapping EDX (shown in (b) green for Ti, (c) blue for O, (d) red for F, and (e) violet for $\mathrm{N}$ element) of the NMP- $\mathrm{Ti}_{1-x-y} \square_{x+y} \mathrm{O}_{2-4(x+y)} \mathrm{F}_{4 x}(\mathrm{OH})_{4 y}$ sample.

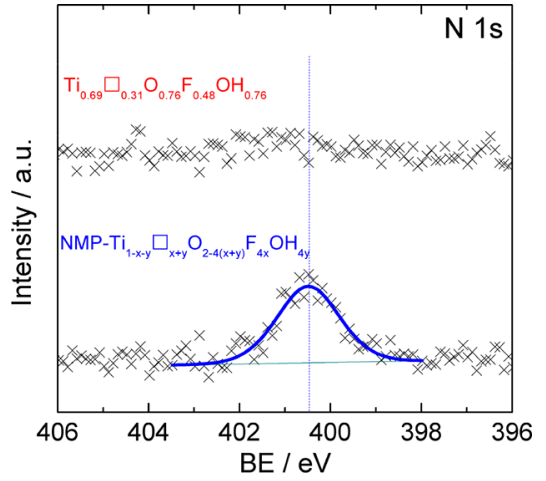

Figure 6. High-resolution $\mathrm{N}$ 1s XPS spectra of anatase $\mathrm{Ti}_{0.69} \square_{0.31} \mathrm{O}_{0.76} \mathrm{~F}_{0.48}(\mathrm{OH})_{0.76}$ before and after NMP treatment.

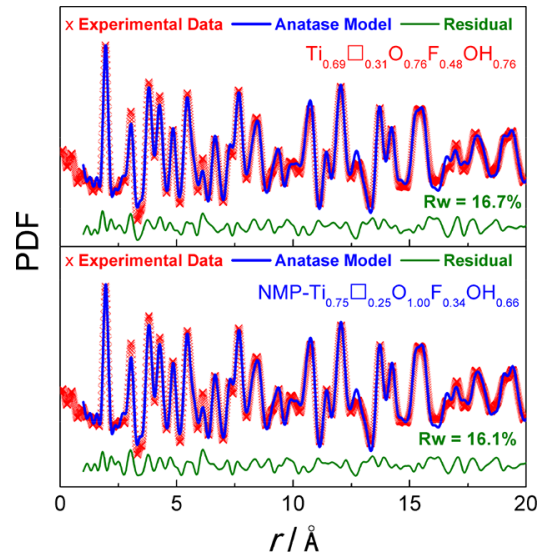

Figure 7. PDF refinements of anatase $\mathrm{Ti}_{0.69} \square_{0.31} \mathrm{O}_{0.76} \mathrm{~F}_{0.48}(\mathrm{OH})_{0.76}$ and NMP- $\mathrm{Ti}_{0.75} \square_{0.25} \mathrm{O}_{1.00} \mathrm{~F}_{0.34}(\mathrm{OH})_{0.66}$.

modification of the chemical composition, that is, a decrease of $\mathrm{F}(x)$ and/or $\mathrm{OH}(y)$ contents.

The treatment with NMP results in a substantial decrease of the fluorine wt \% (from $\sim 13.3$ to $\sim 9.3$ wt \%) measured by ${ }^{19} \mathrm{~F}$ solid-state NMR. According to the general chemical formula $\mathrm{Ti}_{1-x-y} \square_{x+y} \mathrm{O}_{2-4(x+y)} \mathrm{F}_{4 x}(\mathrm{OH})_{4 y}$, the pristine $\mathrm{Ti}_{0.69} \square_{0.31} \mathrm{O}_{0.76} \mathrm{~F}_{0.48}(\mathrm{OH})_{0.76} \quad$ becomes $\mathrm{Ti}_{0.75} \square_{0.25} \mathrm{O}_{1.00} \mathrm{~F}_{0.34}(\mathrm{OH})_{0.66}$ after the NMP treatment. This may be explained by the hydrolysis of water, yielding a partial defluorination of the network according to $\mathrm{Ti}-\mathrm{F}+\mathrm{H}_{2} \mathrm{O} \rightarrow$ $\mathrm{Ti}-\mathrm{OH}+\mathrm{HF}$. Concomitantly, oxolation reaction such as $\mathrm{Ti}-$
$\mathrm{OH}+\mathrm{HO}-\mathrm{Ti} \rightarrow \mathrm{Ti}-\mathrm{O}-\mathrm{Ti}+\mathrm{H}_{2} \mathrm{O}$ occurs, thereby decreasing the $\mathrm{OH}$ content.

The change in the chemical composition was confirmed by XPS analysis. Atomic percentage analysis of $\mathrm{Ti} 2 \mathrm{p}_{3 / 2}, \mathrm{O} 1 \mathrm{~s}$ (that includes $\mathrm{Ti}-\mathrm{O}$ and $\mathrm{Ti}-\mathrm{OH}$ contributions) and $\mathrm{F} 1 \mathrm{~s}$ peak was performed for $\mathrm{Ti}_{0.69} \square_{0.31} \mathrm{O}_{0.76} \mathrm{~F}_{0.48}(\mathrm{OH})_{0.76}$ and NMP$\mathrm{Ti}_{0.75} \square_{0.25} \mathrm{O}_{1.00} \mathrm{~F}_{0.34}(\mathrm{OH})_{0.66}$. The atomic percentages of $\mathrm{Ti} /$ $\mathrm{O} / \mathrm{OH} / \mathrm{F}$ change from $30 / 40 / 5 / 25$ for $\mathrm{Ti}_{0.69} \square_{0.31} \mathrm{O}_{0.76} \mathrm{~F}_{0.48}(\mathrm{OH})_{0.76}$ to $30 / 48 / 3 / 19$ for NMP$\mathrm{Ti}_{0.75} \square_{0.25} \mathrm{O}_{1.00} \mathrm{~F}_{0.34}(\mathrm{OH})_{0.66}$, confirming changes in the sample stoichiometry induced by the treatment.

Thermogravimetric analysis (TGA; Figure S6) showed that the NMP functionalization induces noticeable differences in the thermal behavior, which might be due to a dual effect of the grafting of the NMP molecules and the chemical composition changes.

To better understand the changes occurring during the NMP treatment at the local level, we performed ${ }^{19} \mathrm{~F}$ and ${ }^{1} \mathrm{H}$ solid-state NMR experiments. The ${ }^{19} \mathrm{~F}$ MAS NMR (Figure 8) spectrum of the pristine sample features three lines previously assigned to fluorine atoms coordinated with different numbers of titanium atoms and/or titanium vacancies, namely, species

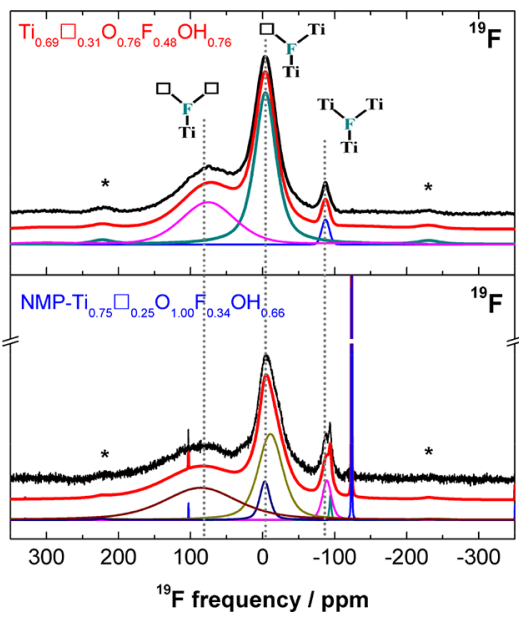

Figure 8. ${ }^{19} \mathrm{~F}$ solid-state MAS $(64 \mathrm{kHz})$ experimental (black) and calculated (red) NMR spectra of $\mathrm{Ti}_{0.69} \square_{0.31} \mathrm{O}_{0.76} \mathrm{~F}_{0.48}(\mathrm{OH})_{0.76}$ and NMP-Ti $i_{0.75} \square_{0.25} \mathrm{O}_{1.00} \mathrm{~F}_{0.34}(\mathrm{OH})_{0.66}$. The asterisks indicate the main spinning side bands. The individual contributions used for the fits are shown below the fits, and parameters used for these fits are given as the Supporting Information (Tables S2 and S3). 
$\mathrm{Ti}_{3}-\mathrm{F}$ at -87 ppm, $\mathrm{Ti}_{2} \square-\mathrm{F}$ at $-4 \mathrm{ppm}$, and $\mathrm{Ti} \square_{2}-\mathrm{F}$ at 76 ppm. ${ }^{20}$ The ${ }^{19} \mathrm{~F}$ MAS NMR spectrum of NMP$\mathrm{Ti}_{0.75} \square_{0.25} \mathrm{O}_{1.00} \mathrm{~F}_{0.34}(\mathrm{OH})_{0.66}$ differs from those of the pristine sample. The three main lines are broader and those assigned to $\mathrm{Ti} \square_{2}-\mathrm{F}$ and $\mathrm{Ti}_{3}-\mathrm{F}$ are asymmetric (and are then fitted with two contributions). The fluorine environments are then even more disordered in NMP-Ti ${ }_{0.75} \square_{0.25} \mathrm{O}_{1.00} \mathrm{~F}_{0.34}(\mathrm{OH})_{0.66}$ than in $\mathrm{Ti}_{0.69} \square_{0.31} \mathrm{O}_{0.76} \mathrm{~F}_{0.48}(\mathrm{OH})_{0.76}$. Because of the decrease of the titanium vacancy rate, the proportion of $\mathrm{Ti}_{2} \square-\mathrm{F}$ decreases and those of $\mathrm{Ti} \square_{2}-\mathrm{F}$ remains constant. An increase of the proportion of $\mathrm{Ti}_{3}-\mathrm{F}$ species is expected but with a lower extent than observed. Indeed, despite the partial defluorination, the sample contains a larger quantity of $\mathrm{Ti}_{3}-\mathrm{F}$ species after the treatment. This further highlights that the treatment is accompanied by a local structural rearrangement. Finally, a resonance appears at $-122.5 \mathrm{ppm}$, attributed to adsorbed $\mathrm{F}^{-}$ ions, ${ }^{43,44}$ resulting from the partial defluorination of the network.

The ${ }^{1} \mathrm{H}$ MAS NMR experimental and reconstructed spectra of the sample before and after the NMP treatment are shown in Figure 9. According to the increase of the chemical shifts

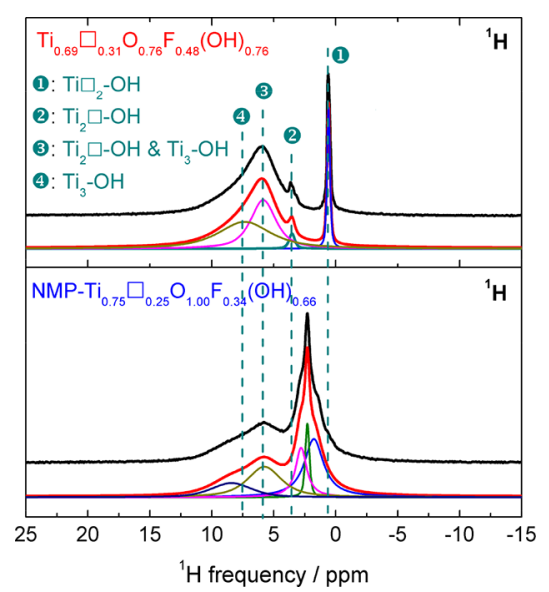

Figure 9. ${ }^{1} \mathrm{H}$ solid-state MAS $(64 \mathrm{kHz})$ experimental (black) and calculated (red) NMR spectra of $\mathrm{Ti}_{0.69} \square_{0.31} \mathrm{O}_{0.76} \mathrm{~F}_{0.48}(\mathrm{OH})_{0.76}$ and NMP-Ti $i_{0.75} \square_{0.25} \mathrm{O}_{1.00} \mathrm{~F}_{0.34}(\mathrm{OH})_{0.66}$. The individual contributions used for the fits are shown below the fits, and parameters used for these fits are given as the Supporting Information (Tables S4 and S5).

upon increasing the number of Ti-surrounding $\mathrm{OH}$ groups observed in anatase by Crocker et $\mathrm{al}^{45}$ and to the assignments (of the species $\mathrm{Ti}_{3}-\mathrm{OH}, \mathrm{Ti}_{2} \square-\mathrm{OH}$, and $\mathrm{Ti} \square_{2}-\mathrm{OH}$ ) in $\mathrm{Ti}_{1-x-y} \square_{x+y} \mathrm{O}_{2-4(x+y)} \mathrm{F}_{4 x}(\mathrm{OH})_{4 y}$ samples ${ }^{21}$ and (of the species $\mathrm{Ti} \square-\mathrm{X}, \mathrm{Ti}_{2}-\mathrm{X}, \mathrm{Ti} \square_{3}-\mathrm{X}, \mathrm{Ti}_{2} \square_{2}-\mathrm{X}, \mathrm{Ti}_{3} \square-\mathrm{X}$, and $\mathrm{Ti}_{4}-\mathrm{X}$ ) in a layered lepidocrocite-type structure, ${ }^{46}$ the species $\mathrm{Ti}_{3}-\mathrm{OH}$, $\mathrm{Ti}_{2} \square-\mathrm{OH}$, and $\mathrm{Ti} \square_{2}-\mathrm{OH}$ are expected to give signals in the ranges of $6-8,4-5$, and $1-2 \mathrm{ppm}$, respectively. On the basis of this trend, the four NMR resonances used to reconstruct the spectrum of the pristine sample have been tentatively assigned (Table S4 and Figure 9). The relative intensities of these NMR resonances point out that $\mathrm{OH}$ groups preferentially form $\mathrm{Ti}_{2} \square-\mathrm{OH}$ and $\mathrm{Ti}_{3}-\mathrm{OH}$ species.

Despite a decrease of the $\mathrm{OH}$ content, because of the grafting of NMP molecules, the ${ }^{1} \mathrm{H}$ MAS NMR spectra recorded before and after the treatment feature similar integrated intensities. Nevertheless, the treatment induces significant changes in the spectrum. First, a broad resonance appears at about $2.3 \mathrm{ppm}$. This new contribution is assigned to the $\mathrm{H}$ atoms of NMP in accordance with their ${ }^{1} \mathrm{H} \delta_{\text {iso }}$ values in solution ranging from 2.0 to $3.4 \mathrm{ppm}$ (Table S5). Second, the NMR signal of the $\mathrm{Ti} \square_{2}-\mathrm{OH}$ species vanishes or, more likely, is substantially reduced and hidden by the broad contribution of NMP. The decrease of the quantity of $\mathrm{Ti} \square_{2}-\mathrm{OH}$ species cannot be explained solely by the decrease of the titanium vacancy rate. Then, it can be assumed that they are preferentially involved in the oxolation reactions.

To probe the presence of PCs in the NMP$\mathrm{Ti}_{0.75} \square_{0.25} \mathrm{O}_{1.00} \mathrm{~F}_{0.34}(\mathrm{OH})_{0.66}$ sample, we performed EPR spectroscopy (Figure 10). Similarly, to the pristine compound,

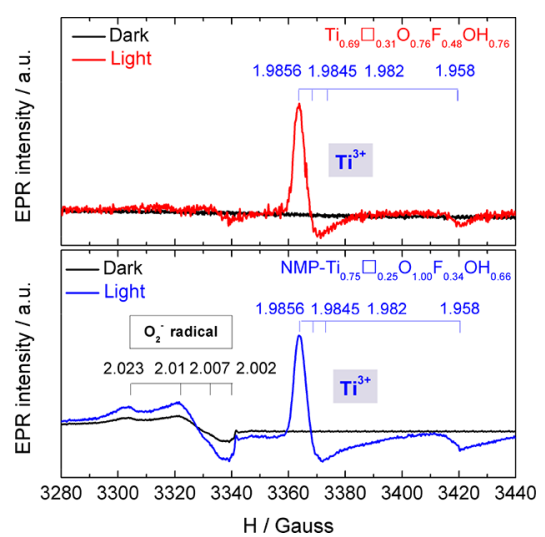

Figure 10. EPR spectra of $\mathrm{Ti}_{0.69} \square_{0.31} \mathrm{O}_{0.76} \mathrm{~F}_{0.48}(\mathrm{OH})_{0.76}$ and NMP$\mathrm{Ti}_{0.75} \square_{0.25} \mathrm{O}_{1.00} \mathrm{~F}_{0.34}(\mathrm{OH})_{0.66}$ anatase at $T=77 \mathrm{~K}$ under dark and illumination.

under dark condition, the EPR spectrum indicates the absence of $\mathrm{Ti}^{\mathrm{III}}$. However, weak EPR signals appear in the range of $3300-3340 \mathrm{G}$, characteristic of $\mathrm{O}_{2}{ }^{-}$radicals, ${ }^{47}$ indicating that the NMP treatment induces changes in reactivity even under dark.

Under illumination, we observed significant changes on the EPR spectrum features. The previous signal at around 3300$3340 \mathrm{G}$, characteristic of $\mathrm{O}_{2}{ }^{-}$radicals, significantly increases. Moreover, similarly to the pristine compound, an intense signal at $3350-3370 \mathrm{G}$ is assigned to $\mathrm{Ti}^{\mathrm{III}}\left(g_{\perp}=1.9845\right.$ and $g_{\|}=$ 1.958). The line width of this signal reflects that these PCs are isolated and mainly localized in the bulk. ${ }^{32}$

A quantitative assessment of the $\mathrm{Ti}^{\mathrm{III}}$ and $\mathrm{O}_{2}{ }^{-}$radicals shows that the NMP treatment significantly modifies the reactivity of anatase. Indeed, the content of $\mathrm{Ti}^{\mathrm{III}}$ centers is $6 \times 10^{16} \mathrm{spin} / \mathrm{g}$ for $\mathrm{Ti}_{0.69} \square_{0.31} \mathrm{O}_{0.76} \mathrm{~F}_{0.48}(\mathrm{OH})_{0.76}$ and $5 \times 10^{17} \mathrm{spin} / \mathrm{g}$ for NMP$\mathrm{Ti}_{0.75} \square_{0.25} \mathrm{O}_{1.00} \mathrm{~F}_{0.34}(\mathrm{OH})_{0.66}$.

The $\mathrm{O}_{2}{ }^{-}$radical content further grows under illumination from $\sim 10^{14} \mathrm{spin} / \mathrm{g}$ for $\mathrm{Ti}_{0.69} \square_{0.31} \mathrm{O}_{0.76} \mathrm{~F}_{0.48}(\mathrm{OH})_{0.76}$ to $3 \times 10^{17}$ spin/g for NMP-Ti $i_{0.75} \square_{0.25} \mathrm{O}_{1.00} \mathrm{~F}_{0.34}(\mathrm{OH})_{0.66}$. Most strikingly, the $\mathrm{Ti} \mathrm{i}^{\mathrm{III}} / \mathrm{O}_{2}{ }^{-}$ratio strongly decreases after the NMP treatment, going from $600\left(=6 \times 10^{16} / 10^{14}\right)$ to $1.67\left(=5 \times 10^{17} / 3 \times\right.$ $\left.10^{17}\right)$. This indicates that the treatment not only increases the concentration of $\mathrm{Ti}^{\mathrm{III}}$ but also most importantly seems to limit the electron-hole recombination. Indeed, the photoexcited electrons are captured by oxygen molecules and $\mathrm{Ti}^{\mathrm{IV}}$ centers, leading to a space separation of the charge carriers and prevents their recombination with photoexcited holes. We do not detect photoexcited holes by the EPR technique, which is probably due to their very short relaxation times and, correspondingly, to the large width of the EPR signal line.

2.2.2. Photoelectrochemistry on NMP-Functionalized Photoanodes. Photoelectrochemical measurements were 

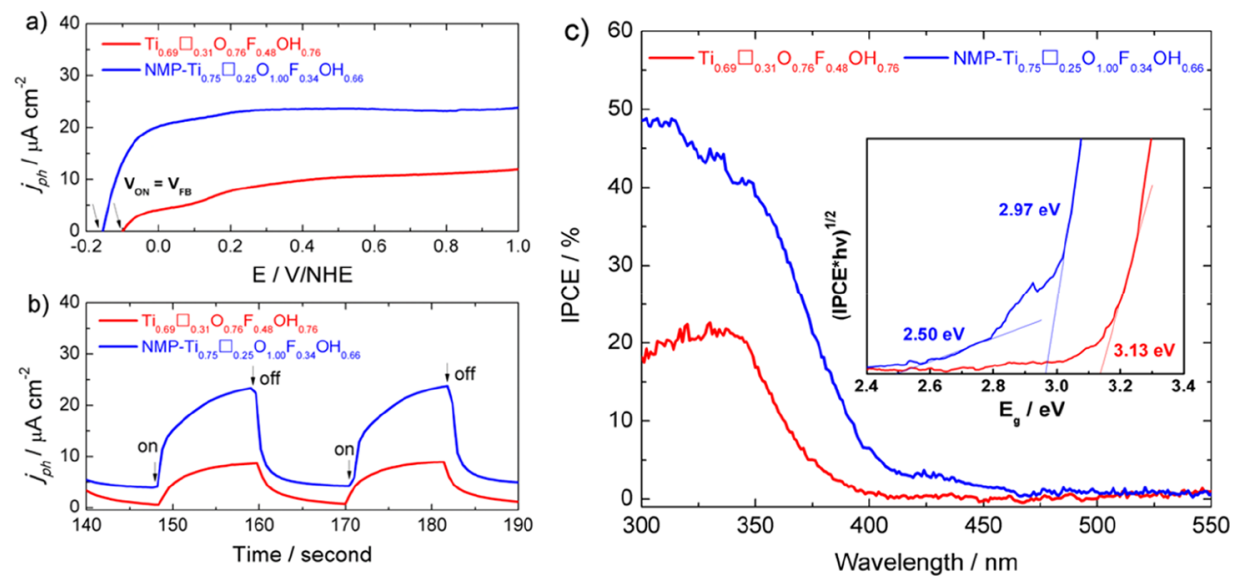

Figure 11. (a) $j_{\mathrm{ph}}-V$ plots under $\mathrm{UV}-$ vis irradiation, and (b) photocurrent response with chopped light (frequency of $0.1 \mathrm{~s}^{-1}$ ) at $1.0 \mathrm{~V} / \mathrm{NHE}$ for $\mathrm{Ti}_{0.69} \square_{0.31} \mathrm{O}_{0.76} \mathrm{~F}_{0.48}(\mathrm{OH})_{0.76}$ and NMP-Ti ${ }_{0.75} \square_{0.25} \mathrm{O}_{1.00} \mathrm{~F}_{0.34}(\mathrm{OH})_{0.66}$ photoanodes in a $\mathrm{N}_{2}$-purged electrolyte $\left(1 \mathrm{M} \mathrm{Na}_{2} \mathrm{SO}_{4}, \mathrm{pH}=5\right)$. Scan rate is 5 $\mathrm{mV} \mathrm{s}^{-1}$. The photoanode geometric surface area is $0.19 \mathrm{~cm}^{2}$. (c) Corrected IPCE spectra, at $1.0 \mathrm{~V} / \mathrm{NHE}$, of $\mathrm{Ti}_{0.69} \square_{0.31} \mathrm{O}_{0.76} \mathrm{~F}_{0.48}(\mathrm{OH})_{0.76}$ and NMP$\mathrm{Ti}_{0.75} \square_{0.25} \mathrm{O}_{1.00} \mathrm{~F}_{0.34}(\mathrm{OH})_{0.66}$ photoanodes. (Inset: Tauc plots for the direct optical transitions of $\mathrm{Ti}_{0.69} \square_{0.31} \mathrm{O}_{0.76} \mathrm{~F}_{0.48}(\mathrm{OH})_{0.76}$ and $\mathrm{NMP}$ $\mathrm{Ti}_{0.75} \square_{0.25} \mathrm{O}_{1.00} \mathrm{~F}_{0.34}(\mathrm{OH})_{0.66}$ photoanodes.)

further performed to understand the impact of the NMP treatment. Figure 11a gathers the electrochemical response under UV-vis light illumination for $\mathrm{Ti}_{0.69} \square_{0.31} \mathrm{O}_{0.76} \mathrm{~F}_{0.48}(\mathrm{OH})_{0.76}$ and NMP $\mathrm{Ti}_{0.75} \square_{0.25} \mathrm{O}_{1.00} \mathrm{~F}_{0.34}(\mathrm{OH})_{0.66}$ anatase. Compared to $\mathrm{Ti}_{0.69} \square_{0.31} \mathrm{O}_{0.76} \mathrm{~F}_{0.48}(\mathrm{OH})_{0.76}, \quad \mathrm{~N} \mathrm{M} \mathrm{P} \mathrm{-}$ $\mathrm{Ti}_{0.75} \square_{0.25} \mathrm{O}_{1.00} \mathrm{~F}_{0.34}(\mathrm{OH})_{0.66}$ shows a 2.5 -fold increase of the photocurrent. Additionally, one should notice that the photocurrent onset potential of NMP$\mathrm{Ti}_{0.75} \square_{0.25} \mathrm{O}_{1.00} \mathrm{~F}_{0.34}(\mathrm{OH})_{0.66}$ is further shifted to a more negative potential, that is, $-0.16 \mathrm{~V}$ versus NHE. A comparison of these values with anatase $\mathrm{TiO}_{2}$ shows a total potential shift of $\Delta E=0.26 \mathrm{~V}$. The electrochemical responses under intermittent light (Figure 11b) have the same behavior for $\mathrm{Ti}_{0.69} \square_{0.31} \mathrm{O}_{0.76} \mathrm{~F}_{0.48}(\mathrm{OH})_{0.76}$ and NMP $\mathrm{Ti}_{0.75} \square_{0.25} \mathrm{O}_{1.00} \mathrm{~F}_{0.34}(\mathrm{OH})_{0.66}$, indicating that the electronhole recombination rate is low compared to anatase $\mathrm{TiO}_{2}$. As it was observed for $\mathrm{Ti}_{0.69} \square_{0.31} \mathrm{O}_{0.76} \mathrm{~F}_{0.48}(\mathrm{OH})_{0.76}$, EPR measurement, under light, indicated the formation of $\mathrm{Ti}^{\mathrm{III}}$ centers where electrons are localized. These electron scavengers allow holes to react directly with water. Furthermore, the onset potential under illumination is negatively shifted, indicating that holes do not have the same reactivity to form $\mathrm{OH}$ radicals. This is a strong indication of a direct charge transfer of holes. This is also supported by the high IPCE values observed for NMP $\mathrm{Ti}_{0.75} \square_{0.25} \mathrm{O}_{1.00} \mathrm{~F}_{0.34}(\mathrm{OH})_{0.66}$ (Figure 11c). Additionally, the IPCE spectrum of NMP-Ti ${ }_{0.75} \square_{0.25} \mathrm{O}_{1.00} \mathrm{~F}_{0.34}(\mathrm{OH})_{0.66}$ sample shows a weak contribution in the visible range up to ca. 475 $\mathrm{nm}$. The Tauc plot (inset in Figure 11c) allows an estimation of a band gap of $2.97 \mathrm{eV}$ with a second threshold featured at $2.50 \mathrm{eV}$ for NMP-Ti $\mathrm{i}_{0.75} \square_{0.25} \mathrm{O}_{1.00} \mathrm{~F}_{0.34}(\mathrm{OH})_{0.66}$, in agreement with the results obtained by UV-vis absorption.

The treatment with NMP results from a surface functionalization and a chemical composition change. These two effects were shown to have distinct consequences on the optical absorption properties. We first observed a red shift of the $\mathrm{O}(2 \mathrm{p})-\mathrm{Ti}(3 \mathrm{~d})$ charge transfer from 3.12 to $3.03 \mathrm{eV}$. Such a red shift can be assigned to the changes in the chemical composition, particularly to the partial defluorination of the network and possibly to the modification of the proton environments. The speciation, that is, the number of neighboring cations, of $\mathrm{OH}$ groups and fluoride can also induce different effects on the band gap energy. The ionocovalent character of $\mathrm{Ti}-\mathrm{X}(\mathrm{X}=\mathrm{F}, \mathrm{OH})$ bonds is dictated by the speciation of these species with $\mathrm{Ti}-\mathrm{X}$ bonds being more covalent in $T_{1} \square_{2}-X$ than in $T_{2} \square_{1}-X$. This point should be more carefully investigated. The second effect observed after the NMP treatment is the appearance of a broad absorption band within the visible range and responsible of the yellow color, leading to a reduced band gap energy at 2.25$2.50 \mathrm{eV}$. We assigned this broad absorption band to the effective grafting of the electron-donating NMP molecules expected to reduce the band gap energy. ${ }^{48}$ Hence, NMP$\mathrm{Ti}_{0.75} \square_{0.25} \mathrm{O}_{1.00} \mathrm{~F}_{0.34}(\mathrm{OH})_{0.66}$ can be better described by a core-shell structure that synergistically favors the formation and separation of electron-hole carriers, similar to the previous report activating anatase $\mathrm{TiO}_{2}$ with a coated carbon shell, producing the same color features and increased photoelectrochemical activities. ${ }^{49}$ It should be noted that after several photoelectrochemical tests, the coloration of the powder did not evolve, suggesting that NMP molecules are strongly bound to the surface.

\section{CONCLUSIONS}

In this work, we report on the optical and photoelectrochemical properties of anatase featuring an oxy-hydroxyfluorinated n e t work with titani u va c a n c i e s $\left(\mathrm{Ti}_{0.69} \square_{0.31} \mathrm{O}_{0.76} \mathrm{~F}_{0.48}(\mathrm{OH})_{0.76}\right)$. Compared to pure $\mathrm{TiO}_{2}$, this compound showed a red shift of $0.08 \mathrm{eV}$ assigned to changes in the ionocovalent character of the titanium-anion bonding. Under illumination, we measured EPR signals characteristic of $\mathrm{Ti}^{\mathrm{III}}$ and radicals $\mathrm{O}_{2}{ }^{-}$which were absent in pure $\mathrm{TiO}_{2}$. We further showed that the ability to induce photogenerated charge carriers in $\mathrm{Ti}_{0.69} \square_{0.31} \mathrm{O}_{0.76} \mathrm{~F}_{0.48}(\mathrm{OH})_{0.76}$ enabled higher photocurrent and more negative shift of the photocurrent onset potential as compared to pure $\mathrm{TiO}_{2}$. We subsequently attempted to modify the surface of the oxy-hydroxyfluorinated anatase by using coordinating NMP molecules. The functionalization, which was shown to be specific to $\mathrm{Ti}_{0.69} \square_{0.31} \mathrm{O}_{0.76} \mathrm{~F}_{0.48}(\mathrm{OH})_{0.76}$, led to a modification of the chemical composition as shown by PDF analysis and ${ }^{1} \mathrm{H} /{ }^{19} \mathrm{~F}$ solid-state NMR. Moreover, we demonstrated the effective 
grafting of the electron-donating NMP molecules, which induces the appearance of a new absorption band in the visible range corresponding to an estimated band gap of 2.25$2.50 \mathrm{eV}$. Hence, the as-prepared composite material showed enhanced photoelectrochemical properties. Such an increasing performance was ascribed to an increasing ability to generate and separate photogenerated charge carriers. This work provides new opportunities in the development of highperformance photocatalysts.

\section{EXPERIMENTAL SECTION}

4.1. Synthesis of $\mathrm{Ti}_{1-x-y} \square_{x+y} \mathrm{O}_{2-4(x+y)} \mathrm{F}_{4 x}(\mathrm{OH})_{4 y}$ and N M P - T i $1-x-y \square_{x+y} \mathrm{O}_{2-4(x+y)} \mathrm{F}_{4 x}(\mathrm{OH})_{4 y}$. $\mathrm{Ti}_{1-x-y} \square_{x+y} \mathrm{O}_{2-4(x+y)} \mathrm{F}_{4 x}(\mathrm{OH})_{4 y}$ was synthesized using the solgel chemistry under solvothermal conditions following previous reports. ${ }^{20,23,50}$ In short, $1.2 \mathrm{~mL}$ of $\mathrm{HF}$ was added to a mixture solution containing $24.8 \mathrm{~mL}$ of isopropanol and 4 $\mathrm{mL}$ of titanium isopropoxide in a $45 \mathrm{~mL}$ Teflon line container. The Teflon line container was loaded into a stainless steel autoclave. After sealing the autoclave, the solution was heated at $90{ }^{\circ} \mathrm{C}$ for $12 \mathrm{~h}$, and the white powder was recovered from the solution. The recovered powder was dried at $80{ }^{\circ} \mathrm{C}$ overnight. Such a low temperature was used to avoid the thermal dehydroxylation of the compound, enabling to preserve a high vacancy concentration. ${ }^{23}$

Anatase functionalized with NMP was obtained by stirring $500 \mathrm{mg}$ of the as-prepared $\mathrm{Ti}_{1-x-y} \square_{x+y} \mathrm{O}_{2-4(x+y)} \mathrm{F}_{4 x}(\mathrm{OH})_{4 y}$ in $20 \mathrm{~mL}$ of NMP at room temperature for 7 days. A yellow powder was recovered from the solution using centrifugation and washed several times with ethanol. The solid was dried at $80{ }^{\circ} \mathrm{C}$ overnight.

For the sake of comparison, anatase $\mathrm{TiO}_{2}$ was synthesized without $\mathrm{HF}$ followed by a post-heat treatment at $300{ }^{\circ} \mathrm{C}$ under air for $2 \mathrm{~h}$ to obtain crystallized anatase $\mathrm{TiO}_{2}$ (Figure S2). The heating temperature was adjusted to obtain pure $\mathrm{TiO}_{2}$ with particle sizes close to that of anatase $\mathrm{Ti}_{1-x-y} \square_{x+y} \mathrm{O}_{2-4(x+y)} \mathrm{F}_{4 x}(\mathrm{OH})_{4 y}$ (Table S1).

4.2. Physical Characterizations. XRD measurements were carried out on a Rigaku diffractometer using $\mathrm{Cu} K \alpha$ radiation in a Bragg-Brentano geometry.

TGA was performed on a METTLER TOLEDO thermogravimetric analyzer under argon atmosphere at a heating rate of $5{ }^{\circ} \mathrm{C} \mathrm{min}{ }^{-1}$ from room temperature to $600{ }^{\circ} \mathrm{C}$.

UV-visible adsorption spectra were recorded using an Agilent Technologies Cary Series spectrophotometer.

Scanning transmission electron microscopy (STEM)-EDX measurement was performed using FEI-TITAN 80-300 kV with ChemiSTEM capability (Cs probe corrector and extreme field emission gun (X-FEG)).

$\mathrm{X}$-ray scattering measurements were performed for PDF analysis at the 11-ID-B beam line at the Advanced Photon Source of Argonne National Laboratory. Similar to previous reports, ${ }^{23,50}$ high-energy X-rays $(\lambda=0.2128 \AA)$ were used to collect data yielding high values of momentum transfer $Q \approx 22$ $\AA^{-1}$. ${ }^{51}$ By the integration of the diffraction images, onedimensional diffraction data were achieved. ${ }^{52}$ After the correction of the background and the Compton scattering, the $G(r)$ function was extracted from the data using PDFgetX2. ${ }^{53}$ The PDF data were refined with the PDFgui software, ${ }^{54}$ and the refined parameters were the scale factor, $s$ ratio, sp diameter (i.e., particle diameter), lattice parameters, oxygen atomic position, titanium (4a Wyckoff site) rate occupancy, and isotropic atomic displacement parameters.
${ }^{1} \mathrm{H}$ and ${ }^{19} \mathrm{~F}$ solid-state magic angle spinning (MAS) NMR experiments were performed in the same way (spectrometer, probe head, pulse sequences, and references) as previously employed for $\mathrm{Ti}_{1-x} \square_{x} \mathrm{O}_{1-4 x}(\mathrm{OH})_{4 x+y} \mathrm{~F}_{2-y} \cdot{ }^{55}{ }^{1} \mathrm{H}$ and ${ }^{19} \mathrm{~F}$ spectra were fitted by using the DMFit software. ${ }^{56}{ }^{19} \mathrm{~F}$ solid-state NMR was also used to quantify the fluorine content on the studied samples by using reference samples. ${ }^{20-22,55}$

XPS characterization was performed with a VG ESCALAB 250 spectrometer at the operating pressure of $3 \times 10^{-9} \mathrm{mbar}$ using a monochromatic $\mathrm{Al} \mathrm{K} \alpha$ radiation $(h \nu=1486.6 \mathrm{eV})$ as the X-ray source, as described in the previous report. ${ }^{23}$ The energy of spectrometer was calibrated with reference to the binding energy (BE) of clean Au sample $\left(\mathrm{Au} 4 \mathrm{f}_{7 / 2}\right.$ at $\left.84 \mathrm{eV}\right)$. The pass energy of the analyzer was $100 \mathrm{eV}$ for survey and 20 $\mathrm{eV}$ for the high-resolution spectra ( $\mathrm{Ti} 2 \mathrm{p}, \mathrm{C} 1 \mathrm{~s}, \mathrm{O} 1 \mathrm{~s}, \mathrm{~N} 1 \mathrm{~s}$, and $\mathrm{F} 1 \mathrm{~s})$. The $\mathrm{BE}$ of peaks was calibrated by setting the $\mathrm{C} 1 \mathrm{~s}$ signal corresponding to $-\mathrm{CH}_{2}-\mathrm{CH}_{2}-$ bonds at $285.0 \mathrm{eV}$. The Advantage software (version 5.954) was employed to perform a peak fitting using a Shirley background and Gaussian/ Lorentzian line shape with a ratio of $70 / 30$.

EPR spectra were recorded by the standard Bruker EPR spectrometer ELEXSYS-500 (X-band, sensitivity is around $\left.\sim 10^{10} \mathrm{spin} / \mathrm{G}\right)$. To illuminate the samples directly in the spectrometer, the optical cavity was used. The samples were positioned in flat ampoules. Etalon $\mathrm{CuCl}_{2} \cdot 2 \mathrm{H}_{2} \mathrm{O}$ was used for the calculation of PC concentration. $\mathrm{Mn}^{2+}$ in $\mathrm{MgO}$ was employed as a reference for $g$-values. The samples were illuminated in situ (directly in the EPR cavity) with a highpressure tungsten lamp in the spectral range 250-1000 nm. The intensity of the illumination was $40 \mathrm{~mW} / \mathrm{cm}^{2}$. The measured temperature was $77 \mathrm{~K}$. Experiments at liquid nitrogen temperature were carried out using a finger cryostat.

4.3. Photoelectrochemical Characterizations. 4.3.1. Photoanodes. A suspension containing $10 \mathrm{mg}$ of active powder and $2 \mathrm{~mL}$ of ethanol was prepared. The mixture was ultrasonically stirred for $2 \mathrm{~h}$ to ensure a homogeneous dispersion; after that, $300 \mu \mathrm{L}$ of suspension was sprayed via an airbrush over the conductive $\mathrm{SnO}_{2}: \mathrm{F}$ (YSUB/ASASHI120/ $1: 10 \times 30 \mathrm{~mm}$, SOLEMS) surface. The resistance of the glass was $80 \Omega /$ sq. The deposit was dried at $100{ }^{\circ} \mathrm{C}$ under air for 2 h. The electric contact of the electrode was done by a copper foil sticker in a region free of active material.

4.3.2. Photoelectrochemical Measurements. Currentpotential curves were measured in a three-electrode photoelectrochemical cell with a working Ti-based porous layer photoanodes, a Pt wire counter electrode, and an $\mathrm{Ag} / \mathrm{AgCl}$ reference electrode. The photoelectrochemical measurements were carried out in an argon-purged $1 \mathrm{M} \mathrm{Na}_{2} \mathrm{SO}_{4}$ electrolyte under UV-vis radiation. A shutter was used during these experiments. The measured potentials versus $\mathrm{Ag} / \mathrm{AgCl}$ were converted to the normal hydrogen electrode (NHE) according to the following equation: $E$ versus $\mathrm{NHE}=E$ versus $\mathrm{Ag} / \mathrm{AgCl}$ $+0.197 \mathrm{~V}$. IPCE action spectra were recorded at $1.0 \mathrm{~V} / \mathrm{NHE}$ under UV-vis illumination at $300-550 \mathrm{~nm}$ with a $150 \mathrm{~W}$ xenon lamp (Spectral Products, ASB-XE-175EX) with an incident irradiation power at the electrode of $34 \mathrm{~mW} / \mathrm{cm}^{2}$. Note that the lower light intensity was used in the present study, generating lower photocurrent, compared to the commonly used light intensity $\left(100 \mathrm{~mW} / \mathrm{cm}^{2}\right)$ in the literature. Generally speaking, the photocurrent increases with the light intensity. Indeed, solar light between 400 and $700 \mathrm{~nm}$ with $2-4 \% \mathrm{UV}$ is called AM 1.5, with ca. $100 \mathrm{~mW} /$ $\mathrm{cm}^{2}$, which is essential for solar cells. In this study, the incident 
power density is only essential to calculate the IPCE by applying the light source photoemission correction. All aqueous solutions were prepared using $18.2 \mathrm{M} \Omega \cdot \mathrm{cm}$ Millipore Milli-Q water, and all measurements were conducted with illumination of the film-electrolyte interface through a 0.19 $\mathrm{cm}^{2}$ mask at the working electrode in the UV-vis light range.

\section{ASSOCIATED CONTENT}

\section{S Supporting Information}

The Supporting Information is available free of charge on the ACS Publications website at DOI: 10.1021/acsomega.9b01219.

XRD patterns, visual appearances, TGA curves, and individual contributions used for the fits of ${ }^{19} \mathrm{~F}$ and ${ }^{1} \mathrm{H}$ MAS NMR spectra (PDF)

\section{AUTHOR INFORMATION}

\section{Corresponding Authors}

*E-mail: jiwei.ma@tongji.edu.cn (J.M.).

*E-mail: christel.laberty@sorbonne-universite.fr (C.L.-R.). *E-mail: damien.dambournet@sorbonne-universite.fr (D.D.).

\section{ORCID 1}

Jiwei Ma: 0000-0003-4209-7667

Christophe Legein: 0000-0001-7426-8817

Arnaud Demortière: 0000-0002-4706-4592

Nicolas Alonso-Vante: 0000-0002-6311-9258

Christel Laberty-Robert: 0000-0003-3230-3164

Damien Dambournet: 0000-0003-3831-2643

\section{Notes}

The authors declare no competing financial interest.

\section{ACKNOWLEDGMENTS}

The research leading to these results has received funding from the French National Research Agency under Idex@Sorbonne University for the Future Investments program (no. ANR-11IDEX-0004-02), the National Science Foundation of China (no. 21805209), and the Russian Foundation for Basic Research (nos. 16-53-00136-Bel-a and 16-32-00800 mol a). Region Ile-de-France is acknowledged for partial funding of the XPS equipment. J.A.D.-R. thanks the National Council for Science and Technology of México (CONACyT) for financial support through scholarship no. 242857 and the University de Poitiers for use of infrastructure, equipment, and facilities in the doctoral stage. The work done at the Advanced Photon Source, an Office of Science User Facility operated for the U.S. Department of Energy (DOE) Office of Science by Argonne National Laboratory, was supported by the U.S. DOE under contract no. DE-AC02-06CH11357.

\section{REFERENCES}

(1) Chen, X.; Mao, S. S. Titanium Dioxide Nanomaterials: Synthesis, Properties, Modifications, and Applications. Chem. Rev. 2007, 107, 2891-2959.

(2) Fujishima, A.; Honda, K. Electrochemical Photolysis of Water at a Semiconductor Electrode. Nature 1972, 238, 37-38.

(3) Chen, X.; Selloni, A. Introduction: Titanium Dioxide $\left(\mathrm{TiO}_{2}\right)$ Nanomaterials. Chem. Rev. 2014, 114, 9281-9282.

(4) Levinson, R.; Berdahl, P.; Akbari, H. Solar spectral optical properties of pigments-Part I: model for deriving scattering and absorption coefficients from transmittance and reflectance measurements. Sol. Energ. Mat. Sol. Cells 2005, 89, 319-349.
(5) Chen, X.; Burda, C. The Electronic Origin of the Visible-Light Absorption Properties of C-, $\mathrm{N}$ - and S-Doped $\mathrm{TiO}_{2}$ Nanomaterials. J. Am. Chem. Soc. 2008, 130, 5018-5019.

(6) Sang, L.; Zhao, Y.; Burda, C. $\mathrm{TiO}_{2}$ Nanoparticles as Functional Building Blocks. Chem. Rev. 2014, 114, 9283-9318.

(7) Liu, G.; Yang, H. G.; Pan, J.; Yang, Y. Q.; Lu, G. Q.; Cheng, H.M. Titanium Dioxide Crystals with Tailored Facets. Chem. Rev. 2014, 114, 9559-9612.

(8) Chen, X.; Shen, S.; Guo, L.; Mao, S. S. Semiconductor-based Photocatalytic Hydrogen Generation. Chem. Rev. 2010, 110, 65036570 .

(9) Asahi, R.; Morikawa, T.; Ohwaki, T.; Aoki, K.; Taga, Y. VisibleLight Photocatalysis in Nitrogen-Doped Titanium Oxides. Science 2001, 293, 269-271.

(10) Pan, J.; Liu, G.; Lu, G. Q. M.; Cheng, H.-M. On the True Photoreactivity Order of $\{001\},\{010\}$, and $\{101\}$ Facets of Anatase $\mathrm{TiO}_{2}$ Crystals. Angew. Chem., Int. Ed. 2011, 50, 2133-2137.

(11) Yang, H. G.; Sun, C. H.; Qiao, S. Z.; Zou, J.; Liu, G.; Smith, S. C.; Cheng, H. M.; Lu, G. Q. Anatase $\mathrm{TiO}_{2}$ single crystals with a large percentage of reactive facets. Nature 2008, 453, 638-641.

(12) Yu, J. C.; Yu, J. G.; Ho, W. K.; Jiang, Z. T.; Zhang, L. Z. Effects of $\mathrm{F}^{-}$doping on the photocatalytic activity and microstructures of nanocrystalline $\mathrm{TiO}_{2}$ powders. Chem. Mater. 2002, 14, 3808-3816.

(13) Menzel, R.; Duerrbeck, A.; Liberti, E.; Yau, H. C.; McComb, D.; Shaffer, M. S. P. Determining the Morphology and Photocatalytic Activity of Two-Dimensional Anatase Nanoplatelets Using Reagent Stoichiometry. Chem. Mater. 2013, 25, 2137-2145.

(14) Calatayud, D. G.; Jardiel, T.; Peiteado, M.; Illas, F.; Giamello, E.; Palomares, F. J.; Fernández-Hevia, D.; Caballero, A. C. Synthesis and Characterization of Blue Faceted Anatase Nanoparticles through Extensive Fluorine Lattice Doping. J. Phys. Chem. C 2015, 119, 21243-21250.

(15) Czoska, A. M.; Livraghi, S.; Chiesa, M.; Giamello, E.; Agnoli, S.; Granozzi, G.; Finazzi, E.; Valentin, C. D.; Pacchioni, G. The Nature of Defects in Fluorine-Doped $\mathrm{TiO}_{2}$. J. Phys. Chem. C 2008, 112, 89518956.

(16) Li, D.; Haneda, H.; Labhsetwar, N. K.; Hishita, S.; Ohashi, N. Visible-light-driven photocatalysis on fluorine-doped $\mathrm{TiO}_{2}$ powders by the creation of surface oxygen vacancies. Chem. Phys. Lett. 2005, $401,579-584$.

(17) Tosoni, S.; Fernandez Hevia, D.; González Díaz, Ó.; Illas, F. Origin of Optical Excitations in Fluorine-Doped Titania from Response Function Theory: Relevance to Photocatalysis. J. Phys. Chem. Lett. 2012, 3, 2269-2274.

(18) Liu, B.; Cheng, K.; Nie, S.; Zhao, X.; Yu, H.; Yu, J.; Fujishima, A.; Nakata, K. Ice-Water Quenching Induced $\mathrm{Ti}^{3+}$ Self-doped $\mathrm{TiO}_{2}$ with Surface Lattice Distortion and the Increased Photocatalytic Activity. J. Phys. Chem. C 2017, 121, 19836-19848.

(19) Liu, B.; Zhao, X.; Zhao, Q.; He, X.; Feng, J. Effect of heat treatment on the UV-vis-NIR and PL spectra of $\mathrm{TiO}_{2}$ films. J. Electron. Spectrosc. Related Phenom. 2005, 148, 158-163.

(20) Li, W.; Corradini, D.; Body, M.; Legein, C.; Salanne, M.; Ma, J.; Chapman, K. W.; Chupas, P. J.; Rollet, A.-L.; Julien, C.; et al. High Substitution Rate in $\mathrm{TiO}_{2}$ Anatase Nanoparticles with Cationic Vacancies for Fast Lithium Storage. Chem. Mater. 2015, 27, 50145019.

(21) Li, W.; Body, M.; Legein, C.; Borkiewicz, O. J.; Dambournet, D. Atomic Insights into Nanoparticle Formation of Hydroxyfluorinated Anatase Featuring Titanium Vacancies. Inorg. Chem. 2016, 55, 71827187.

(22) Li, W.; Body, M.; Legein, C.; Borkiewicz, O. J.; Dambournet, D. Solvothermal Temperature Drives Morphological and Compositional Changes through Dehydroxyfluorination in Anatase Nanoparticles. Eur. J. Inorg. Chem. 2017, 2017, 192-197.

(23) Ma, J.; Li, W.; Morgan, B. J.; Światowska, J.; Baddour-Hadjean, R.; Body, M.; Legein, C.; Borkiewicz, O. J.; Leclerc, S.; Groult, H.; et al. Lithium Intercalation in Anatase Titanium Vacancies and the Role of Local Anionic Environment. Chem. Mater. 2018, 30, 30783089. 
(24) Scanlon, D. O.; Dunnill, C. W.; Buckeridge, J.; Shevlin, S. A.; Logsdail, A. J.; Woodley, S. M.; Catlow, C. R. A.; Powell, M. J.; Palgrave, R. G.; Parkin, I. P.; et al. Band alignment of rutile and anatase $\mathrm{TiO}_{2}$. Nat. Mater. 2013, 12, 798-801.

(25) Corradini, D.; Dambournet, D.; Salanne, M. Tuning the Electronic Structure of Anatase Through Fluorination. Sci. Rep. 2015, $5,11553$.

(26) Demourgues, A.; Penin, N.; Durand, E.; Weill, F.; Dambournet, D.; Viadere, N.; Tressaud, A. New Titanium Hydroxyfluoride $\mathrm{Ti}_{0.75}(\mathrm{OH})_{1.5} \mathrm{~F}_{1.5}$ as a UV Absorber. Chem. Mater. 2009, 21, 12751283.

(27) Chiesa, M.; Paganini, M. C.; Livraghi, S.; Giamello, E. Charge trapping in $\mathrm{TiO}_{2}$ polymorphs as seen by Electron Paramagnetic Resonance spectroscopy. Phys. Chem. Chem. Phys. 2013, 15, 94359447.

(28) Konstantinova, E. A.; Kokorin, A. I.; Sakthivel, S.; Kisch, H.; Lips, K. Carbon-Doped Titanium Dioxide: Visible Light Photocatalysis and EPR Investigation. Chimia 2007, 61, 810-814.

(29) Macdonald, I. R.; Rhydderch, S.; Holt, E.; Grant, N.; Storey, J. M. D.; Howe, R. F. EPR studies of electron and hole trapping in titania photocatalysts. Catal. Today 2012, 182, 39-45.

(30) Berger, T.; Sterrer, M.; Diwald, O.; Knözinger, E.; Panayotov, D.; Thompson, T. L.; Yates, J. T. Light-Induced Charge Separation in Anatase $\mathrm{TiO}_{2}$ Particles. J. Phys. Chem. B 2005, 109, 6061-6068.

(31) Hurum, D. C.; Agrios, A. G.; Gray, K. A.; Rajh, T.; Thurnauer, M. C. Explaining the Enhanced Photocatalytic Activity of Degussa P25 Mixed-Phase $\mathrm{TiO}_{2}$ Using EPR. J. Phys. Chem. B 2003, 107, $4545-4549$.

(32) Weil, J. A.; Bolton, J. R. Electron Paramagnetic Resonance: Elementary Theory and Practical Applications, 2nd ed.; John Wiley \& Sons, Inc., 2006.

(33) Kong, M.; Li, Y.; Chen, X.; Tian, T.; Fang, P.; Zheng, F.; Zhao, $\mathrm{X}$. Tuning the Relative Concentration Ratio of Bulk Defects to Surface Defects in $\mathrm{TiO}_{2}$ Nanocrystals Leads to High Photocatalytic Efficiency. J. Am. Chem. Soc. 2011, 133, 16414-16417.

(34) Peter, L. M. Dynamic aspects of semiconductor photoelectrochemistry. Chem. Rev. 1990, 90, 753-769.

(35) Berger, T.; Monllor-Satoca, D.; Jankulovska, M.; LanaVillarreal, T.; Gómez, R. The Electrochemistry of Nanostructured Titanium Dioxide Electrodes. ChemPhysChem 2012, 13, 2824-2875.

(36) Chen, Z.; Jaramillo, T. F.; Deutsch, T. G.; KleimanShwarsctein, A.; Forman, A. J.; Gaillard, N.; Garland, R.; Takanabe, K.; Heske, C.; Sunkara, M.; et al. Accelerating materials development for photoelectrochemical hydrogen production: Standards for methods, definitions, and reporting protocols. J. Mater. Res. 2010, $25,3-16$.

(37) Oliva, F. Y.; Avalle, L. B.; Santos, E.; Cámara, O. R. Photoelectrochemical characterization of nanocrystalline $\mathrm{TiO}_{2}$ films on titanium substrates. J. Photochem. Photobiol. A 2002, 146, 175188.

(38) Landmann, M.; Rauls, E.; Schmidt, W. G. The electronic structure and optical response of rutile, anatase and brookite $\mathrm{TiO}_{2}$. J. Phys. Condens. Matter 2012, 24, 195503.

(39) Barolo, G.; Livraghi, S.; Chiesa, M.; Paganini, M. C.; Giamello, E. Mechanism of the Photoactivity under Visible Light of N-Doped Titanium Dioxide. Charge Carriers Migration in Irradiated $\mathrm{N}-\mathrm{TiO}_{2}$ Investigated by Electron Paramagnetic Resonance. J. Phys. Chem. C 2012, 116, 20887-20894.

(40) Dimitrijevic, N. M.; Poluektov, O. G.; Saponjic, Z. V.; Rajh, T. Complex and Charge Transfer between $\mathrm{TiO}_{2}$ and Pyrroloquinoline Quinone. J. Phys. Chem. B 2006, 110, 25392-25398.

(41) Louette, P.; Bodino, F.; Pireaux, J.-J. Poly(pyrrole) (PPY) XPS Reference Core Level and Energy Loss Spectra. Surf. Sci. Sepctra 2005, 12, 84-89.

(42) Beamson, G.; Briggs, D. High Resolution XPS of Organic Polymers : The Scienta ESCA300 Database; Wiley: Chichester, England, 1992.

(43) König, R.; Scholz, G.; Kemnitz, E. Local Structural Changes in Aluminum Isopropoxide Fluoride Xerogels and Solids as a
Consequence of the Progressive Fluorination Degree. J. Phys. Chem. C 2009, 113, 6426-6438.

(44) Kao, H.-M.; Liao, Y.-C. Direct Solid-State NMR Observation of Tetrahedral Aluminum Fluorides in Zeolite HY Fluorinated by Ammonium Fluoride. J. Phys. Chem. C 2007, 111, 4495-4498.

(45) Crocker, M.; Herold, R. H. M.; Wilson, A. E.; Mackay, M.; Emeis, C. A.; Hoogendoorn, A. M. ${ }^{1} \mathrm{H}$ NMR spectroscopy of titania. Chemical shift assignments for hydroxy groups in crystalline and amorphous forms of $\mathrm{TiO}_{2}$. J. Chem. Soc., Faraday Trans. 1996, 92, $2791-2798$

(46) Ma, J.; Reeves, K. G.; Porras Gutierrez, A.-G.; Body, M.; Legein, C.; Kakinuma, K.; Borkiewicz, O. J.; Chapman, K. W.; Groult, H.; Salanne, M.; et al. Layered Lepidocrocite Type Structure Isolated by Revisiting the Sol-Gel Chemistry of Anatase $\mathrm{TiO}_{2}$ : A New Anode Material for Batteries. Chem. Mater. 2017, 29, 8313-8324.

(47) Carter, E.; Carley, A. F.; Murphy, D. M. Evidence for $\mathrm{O}^{2-}$ Radical Stabilization at Surface Oxygen Vacancies on Polycrystalline $\mathrm{TiO}_{2}$. J. Phys. Chem. C 2007, 111, 10630-10638.

(48) Hendon, C. H.; Tiana, D.; Fontecave, M.; Sanchez, C.; D’arras, L.; Sassoye, C.; Rozes, L.; Mellot-Draznieks, C.; Walsh, A. Engineering the Optical Response of the Titanium-MIL-125 MetalOrganic Framework through Ligand Functionalization. J. Am. Chem. Soc. 2013, 135, 10942-10945.

(49) Zhao, L.; Chen, X.; Wang, X.; Zhang, Y.; Wei, W.; Sun, Y.; Antonietti, M.; Titirici, M.-M. One-Step Solvothermal Synthesis of a Carbon@ $\mathrm{TiO}_{2}$ Dyade Structure Effectively Promoting Visible-Light Photocatalysis. Adv. Mater. 2010, 22, 3317-3321.

(50) Koketsu, T.; Ma, J.; Morgan, B. J.; Body, M.; Legein, C.; Dachraoui, W.; Giannini, M.; Demortière, A.; Salanne, M.; Dardoize, F.; et al. Reversible magnesium and aluminium ions insertion in cation-deficient anatase $\mathrm{TiO}_{2}$. Nat. Mater. 2017, 16, 1142-1148.

(51) Chupas, P. J.; Qiu, X.; Hanson, J. C.; Lee, P. L.; Grey, C. P.; Billinge, S. J. L. Rapid-acquisition pair distribution function (RAPDF) analysis. J. Appl. Crystallogr. 2003, 36, 1342-1347.

(52) Hammersley, A. P.; Svensson, S. O.; Hanfland, M.; Fitch, A. N.; Hausermann, D. Two-dimensional detector software: From real detector to idealised image or two-theta scan. High Press. Res. 1996, $14,235-248$.

(53) Qiu, X.; Thompson, J. W.; Billinge, S. J. L. PDFgetX2: a GUIdriven program to obtain the pair distribution function from X-ray powder diffraction data. J. Appl. Crystallogr. 2004, 37, 678.

(54) Farrow, C. L.; Juhas, P.; Liu, J. W.; Bryndin, D.; Božin, E. S.; Bloch, J.; Proffen, T.; Billinge, S. J. L. PDFfit2 and PDFgui: computer programs for studying nanostructure in crystals. J. Phys. Condens. Matter 2007, 19, 335219.

(55) Li, W.; Body, M.; Legein, C.; Dambournet, D. Identify OH groups in $\mathrm{TiOF}_{2}$ and their impact on the lithium intercalation properties. J. Solid State Chem. 2017, 246, 113-118.

(56) Massiot, D.; Fayon, F.; Capron, M.; King, I.; Le Calvé, S.; Alonso, B.; Durand, J.-O.; Bujoli, B.; Gan, Z.; Hoatson, G. Modelling one- and two-dimensional solid-state NMR spectra. Magn. Reson. Chem. 2002, 40, 70-76. 